\title{
SOME ASPECTS OF LEPTOSPIROSIS IN MALAYSIA
}

\author{
With Reference to its Military Significance * \\ Brigadier JOHN MACKAY-DICK, O.B.E., M.D., F.R.C.P. † \\ Consultant in Medicine
}

SUMMARY: In the jungles of Malaysia there is a large natural reservoir of leptospirosis, a disease of significance as a military hazard particularly when 'mass' infections may necessitate the withdrawal of a patrol from operations. Portals of entry are the skin, conjunctiva, nasal and buccal mucosa, anus and genitals. Conditions of special exposure, when chemoprophylaxis or abortive treatment may be considered, and preventive measures, are described as well as the infectious environment with special reference to water as a vector, and where and when it may be considered safe to bathe. The case incidence is proportional to the amount of time spent on jungle operations; which may explain the variation in the incidence of leptospirosis in British Security Forces in operations in Malaysia (1948-1961) and in United States Army personnel in Vietnam.

Subclinical cases occur; but normally in at least 85 per cent of cases leptospirosis is a benign self limited febrile disease ( 3 to 15 days) with inconstant secondary fever of interdeterminate origin, varying duration and associated with recrudescence of symptoms. An occasional death occurs. Probably over 90 per cent of cases are anicteric. Significant lower nephron nephrosis occurs in around 6 per cent of cases; and haemorrhagic phenomena are present in less than $\mathbf{2 0}$ per cent. Fulminating haemorrhagic pneumonia is rare. Multiple and repeated infections occur. Generally any febrile illness in patients from leptospiral environments characterised by headache, myalgia, conjunctival suffusion and gastrointestinal symptoms, in the presence of urinary abnormalities, warrants the diagnosis of leptospirosis unless proven otherwise; but the urine may be normal or may just show a trace of albumin. The key to successful treatment is early diagnosis and adequate chemotherapy, using crystalline penicillin parenterally in the predominantly septicaemic phase of the illness together with the maintenance of water and electrolyte balance and otherwise masterly inactivity in the normal case; no matter when adequate penicillin is given in the illness there is no secondary fever, no residual impairment of renal function and no late complications such as iritis, etc. Renal dialysis is life saving in severe lower nephron nephrosis. Vaso-constrictors are to be avoided in the treatment of hypotension as they may be lethal. Prednisone may be of value in complicated cases and as a 'cover ' for penicillin, in cases treated early, when there occurs a characteristic Herxheimer-like reaction.

* Extracts from addresses on Leptospirosis to the Royal Society of Tropical Medicine and Hygiene, Edinburgh Branch, December 1967; and to a World Health Organisation Training Course on Occupational Health in Agriculture held at the University of Dundee, October 1968; and from a M.D. Thesis, University of Edinburgh, 1969, entitled 'Some Aspects of Leptospirosis in the Jungles of Eastern and Western Malaysia: A Hazard of Military Significance'.

$\dagger$ Present address 26 Kingsburgh Road, Edinburgh EH12 6DZ. 
Laboratory diagnosis is normally by blood culture and serological tests; but with early and adequate penicillin therapy peak serological titres may be so low, and in some cases serum antibodies may not be detectable in the ensuing weeks, that the only means of a diagnosis may be a positive blood culture; yet the latter may be negative when blood samples are taken after penicillin has been given or because of contaminants, and in such circumstances the Herxheimer-like reaction may be of special diagnostic significance.

A knowledge by Commanders at all levels on Active Service in the jungles of Eastern and Western Malaysia of reservoir hosts of infection, of leptospiral environments, of sources and routes of infection, of preventive measures and evasive action regarding leptospirosis, as well as the extremes of the incubation period (4 to 21 days) are of significant importance particularly when the effectiveness of a jungle patrol may be neutralised to such an extent that it has to be withdrawn from an important operation and so jeopardise its success.

\section{The operational hazard of leptospirosis to the soldier}

Water is a vector of this disease to man and the soldier in jungle operations is necessarily variously exposed to it. Baker (1965) has shown that for occasional brief periods streams following rainfall and flooding have been found to be far more infectious than the swamp. This suggested a hypothetical reservoir of leptospirae that was washed out by the flood. His further investigations revealed a frequency and intensity of infectiousness in the shore sand which explains the infectiousness of the flooded stream. Baker (1965) also established that foci of high infectiousness could be found along the smallest tributaries high on the forested mountain sides, and the generalised leptospiral contamination of the Malaysian tropical rainforest.

The factors that contribute to the formation and maintenance of water foci are imperfectly understood. Some of the conventional ideas of the potential infectiousness of stagnant waters and slow moving streams in endemic foci were not necessarily valid in different ecological foci of infection. For example the infectiousness of rapidly flowing water in jungle (and other) foci of infection has been demonstrated (WHO, 1968). Moreover, the infectiousness of these water increases at the time of flood (Baker, 1965 and WHO, 1968).

When is it safe to bathe in fresh water?

There is no ready way of determining whether a pool, reservoir, lake or river is safe to bathe in because of its $\mathrm{pH}$ or chemical content; water will definitely be free from leptospires only when a free chlorine content can be demonstrated as for drinking water. Streams in spate are always to be avoided but water from them at basal levels or at least six hours after flooding may be used, as a calculated risk, for ablution purposes or for the washing of clothes. Pools or lakes for bathing are always to be used in preference to streams in any state. Whilst preparing for bathing there should be no sitting on the ground or walking barefoot; and every opportunity should be taken to use rocks and wooden or bamboo platforms to avoid contact of the skin with soil or sand, particularly the bank. Control over bathing sites is a sine qua non and where possible there should always be some platform approach to the water.

A lake, pond or reservoir may normally be safe for bathing at least 24 hours after flood waters have run into it because of the dilution factor and the 1 to $2 \log$ daily decrement of leptospires; such waters are safer for bathing than a stream and certainly safer than a stream in flood (Baker and Tigert, 1967-personal communication). 
It is of interest to record that in Sarawak there was a wide expanse of water known as the Bau Lake. This is said to be a 200 feet deep gold mine, flooded by a spring in its base, widely exposed and unprotected from the sun. It is almost certainly noninfective solely on account of its size, widely exposed position and unprotected from the tropical sun, dilution factor from any contaminating flood water and the daily decrement of any added leptospires; and not from any $\mathrm{pH}$ or chemical content factor. It was used as a lido which included the following facilities, namely a wooden platform extending from the bank together with a springboard, a chute the summit of which was reached by a ladder on the bank so that individuals would slide straight into the water, also a covered raft, pulled to the bank by a rope, on which individuals could embark. It could then be rowed well away from the bank and used for diving purposes. Accordingly there was no contact with the damp part of the bank or with the bottom of Bau Lake due to its depth. We therefore turned a blind eye to this bathing pool for the good reason that no cases of leptospirosis had been traced to it during the period of the Indonesian Confrontation (1963-1966).

The risk of leptospirosis is ever present but it is necessary to balance the relative risks against operational needs as well as morale, and hygiene of the body.

Medical advice may conflict with military requirements and the Commander must be fully briefed before taking the decision involving a calculated risk; but it is in such circumstances of special risk to leptospirosis, with significant adverse consequences on combat effectiveness, that oral penicillin (or terramycin) may be of value prophylactically.

Where possible streams should be crossed when not in flood or not until six hours at least after flooding and then only at their narrowest point and shallowest depth, with no splashing and water not to come in contact with the bare skin, nasat or buccal mucosa or conjunctiva; while immersion in whole or in part is particularly to be avoided.

When a river is in spate and a weapon is dropped during river-crossing then in view of past experience of the high incidence of leptospirosis following repeated diving to retrieve the weapon(s) the patrol Commander is left with three possible lines of action, namely accept the weapon as lost but that could result in disciplinary action; only 25 per cent of the patrol to endeavour to retrieve it by repeated diving and to be given abortive treatment with oral penicillin or oral terramycin: or the entire patrol to endeavour to retrieve the weapon(s) by repeated diving and all to be given chemoprophylaxis. Whether or not chemoprophylaxis should be ordered might depend on the day of the patrol and its further duration bearing in mind that the incubation period of leptospirosis may vary from 4 to 21 days or so. At this early stage of infection the number of leptospires in the blood would be minimal so that the Herxheimer-like reaction which follows chemotherapy with penicillin given early in clinical leptospirosis would be negligible even if detectable.

The following are examples of 'mass' infections with leptospirosis the result of river crossings:-

The Regimental Medical Officer of a Highland Regiment in Sarawak (Weeks, -personal communication) reported that two platoons went in hot pursuit of the enemy during an enemy incursion. The fastest means of covering the ground, especially at night, was to wade upstream. They spent a total of about 12 hours in the water, immersed to the knees, and occasionally up to the neck. The water level was high. The stream 
passed through uninhabited jungle. Five days later the first case of leptospirosis appeared. The final count was 15 cases out of 52 all ranks ( 29 per cent) taking part in this patrol (Moorhouse, 1966 - personal communication).

A patrol of 21 Royal Marine Commandos were crossing a river in spate in Sarawak two weapons were dropped and the men dived in relays over a period of four hours in an endeavour to retrieve the lost weapons. The first man to go sick with leptospirosis did so on the ninth or tenth day following the incident. When the sixth case fell sick the Commanding Officer of the unit decided that he must visit them and with the possibility of further cases occurring making the troop ineffective, he had: no alternative but to order the patrol to return to base. In all there were nine cases of leptospirosis in this patrol (43 per cent) of 21 all ranks. Leptospirosis had achieved what the Indonesians had never achieved. At Annex ' $A$ ' and Annex ' $B$ ' to this paper are reports by the unit Commanding Officer (Taplin, 1966) and the patrol Commander (Garrod, 1966) on this incident, which combined must be a classical description of the hazard of river crossing in so far as the natural history and circumstances of infection with leptospirosis is concerned.

Understandably training in river crossing by soldiers was also a hazard. Out of 105 men practising river crossing, 8 fell ill within a few days. The Commanding Officer said that such a casualty rate was unacceptable and could we not give his men 'something to take ' during periods of special exposure to leptospirosis? We decided on chemoprophylaxis with penicillin and Telford (1966) reports as follows:-

\section{Leptospirosis 1st Bn Blankshires}

"A recent outbreak of leptospirosis in one company of the 1st Bn Blankshires followed the now familiar pattern.

The company of 105 men had been practising river crossing and swimming under operational conditions in the Tebakang area of the First Division of Sarawak for about five weeks.

Within a period of five days, 8 soldiers developed clinical signs of leptospirosis, all of which were later confirmed by the serological investigations. The degree of severity varied from severe to mild, and all men are now fit.

Although the incubation period varied in the soldiers, it is highly probable that they were all infected at the same time. This would indicate that the infectivity of a river varies from day to day, as these soldiers had been training in the same river for five weeks. The concentration of leptospires in the river at any one time is presumably influenced by rainfall somewhat up river.

These men are continuing their training in swimming and river crossing in the same river. In order to reduce the chances of being infected with leptospirosis, prophylactic peniciliin has been used.

Training takes place normally over two lots of five days, then a break, and another period of training. The dosage of penicillin being tried now is $500 \mathrm{mg}$ of oral penicillin 5 times during the day. This is being supervised in the same way as paludrine administration for malaria. The penicillin is taken every day they are training and for a minimum of four days. The first daily dose is taken at 0700 hours, which is half an hour before training starts and the last dose is taken four hours after training is finished for the day. 
The question of giving penicillin by injection either as depot or seclopen penicillin was discussed at much length and as the administrative difficulties of giving constant injections to these soldiers were considerable, we decided therefore to try oral penicillin under strict supervision.

There are just over 100 soldiers involved in this trial, but there are No controls. The requirement is to keep the company free from infection as far as possible and the role of the company does not really allow us to leave half the company unprotected during their training.

We are naturally keeping a close and interested watch on all those soldiers and I shall keep you informed about any developments whether good or bad.

What we are doing is clearly not good medicine but $I$ think it is the only medical solution to a necessary training problem."

There were no cases of sensitivity to oral penicillin, and there were no cases of leptospirosis in those having oral penicillin prophylactically. As hostilities soon ceased we had no further opportunities in Eastern Malaysia to pursue this investigation further; but it is interesting to note that Turner (1969) recommends that abortive treatment with penicillin should be considered in cases of special exposure to leptospirosis.

\section{Vaccination}

Vaccination has been considered successful in the Italian rice fields (Babudieri, 1957) where those at risk are concentrated at work; but differences in types and more variable exposure have operated against its effectiveness, and, indeed use elsewhere. Nevertheless in areas, such as Eastern and Western Malaysia, where multiple leptospirosis occurs efforts should be made to develop multivalent vaccines containing the fewest possible serotypes and having a broad antigenic spectrum (W.H.O., 1968).

\section{Medical intelligence}

In preparing a guide for regimental officers on leptospirosis, its cause, sources of infection, modes of infection and prevention, its incidence and military significance, we should bear in mind that in the Malayan Emergency (1948-1961) McCrumb et al (1957) showed that thirty-five per cent of all febrile illnesses among military personnel were due to leptospirosis, and that forty per cent of all febrile illnesses which were not malaria were due to leptospirosis; also that in the daily observation of one battalion the amount of leptospirosis was directly correlated with the amount of jungle duty; that on the average there was approximately one case of laboratory proved leptospirosis per battalion per day of jungle duty, while four out of five cases were men who had been on jungle duty in the two weeks prior to onset (Lancet, 1960 and Baker, 1965): On the other hand Mackay-Dick and Robinson (1957) found that 96 per cent of 84 laboratory proved cases of leptospirosis in soldiers first reported sick within 10 days of returning from jungle patrol. The remainder were living in jungle camps. It will therefore be seen that in the provisional diagnosis of leptospirosis in Service personnel their movement or locational history is of much significance. Of course, in the Army, territorial-residentialoccupational history has always been a most important aspect of patient examination. Where have you been? What is your occupation and its hazards and what are your hobbies and recreations are stock questions. 
Commanders at all levels, and desirably all ranks, must know:-

How leptospirosis is spread: The sources of infection and their avoidance: That, ideally, water for all purposes should be clean, filtered and adequately chlorinated: The value of collecting rain water for all purposes and the necessity for storing it free from contamination: That there should be no contact of the bare skin with soil, sand or infected water, and that sitting on the ground should be avoided. The precautions to be taken in river crossing and the anticipated high incidence of leptospirosis when there is repeated diving to retrieve weapons dropped in the river particularly when the river is in spate: Where and when it is relatively safe to bathe, why some form of footgear should be worn and why there should be some form of platform or diving board over the water so as to keep clear of the bank: How all things edible should be stored off the ground and in protected meat safes with roofs impermeable to the urine of rats and other animals: That mosquito nets do not just protect from mosquitos, other insects, snakes or animals, but also from rats which may bite the sleeping soldier and urinate on the wound at the same time and so spread leptospirosis: Why all waste food and garbage must be burnt and buried in deep waste pits and why there must be a constant war on rats and rodents ensuring that nothing which rats find edible are left unprotected and that includes toilet soap and even the binding on the handle of a squash racket.

Elsewhere (Mackay-Dick and Watts, 1949, Mackay-Dick and Robinson, 1957, 1959a, 1959b and Mackay-Dick, 1969) we have already made observations on the clinical features and clinical laboratory diagnosis of leptospirosis; as well as on repeated attacks, concurrent infections with two serotypes and the dramatic therapeutic effects of early and adequate penicillin therapy when there occurs the characteristic Herxheimer-like reaction which we have termed the diagnostic penicillin-leptospiral response; also that in all cases of letospirosis treated with adequate penicillin we have had no fatal cases, no cases of secondary fever (so-called relapses) and no late complications, for example iritis; and we have recorded a second penicillin leptospiral response when treatment was interrupted and penicillin later given again in the same patient.

Our views on the efficacy of penicillin therapy in leptospirosis have been supported, among others, by Cook (1959), Doherty (1955 and 1960), Gsell (1966) and Turner (1967 and 1969).

We have also emphasised that with the early exhibition of adequate penicillin therapy antibodies may be well below diagnostic level or not even be detectable in the ensuing weeks; and therefore in cases where blood culture is contaminated or where penicillin has been given before blood samples have been taken a diagnosis may have to be made on clinical grounds alone supported by the penicillin-leptospiral response in most cases where treatment has been begun on or before day 5 of the illness.

\section{Comparison with the incidence of Leptospirosis in other areas of the Far East}

The French Indo-Chinese war focused attention on this disease in Vietnam. Three epidemics occurred in the Mekong Delta in 1950, 1951 and 1952; also in one operation in Vietnam 126 men, nearly one quarter of the effective force, were incapacitated (de Lajudie et al, 1953). Delahouse (1961) published a summary of 153 cases of leptospirosis occurring in military personnel during the operations in Tonkin and Laos between 1953 and 1954. In another report by Spinu et al (1963) 121 cases of leptospirosis were 
recorded in North Vietnam among members of a military woodcutting detail during June and through September 1959.

An outbreak of 168 cases of anicteric leptospirosis on the outskirts of Chunking, China was reported by Wang et al (1965). Of interest in this epidemic were the striking pulmonary manifestations. 83 patients had respiratory involvement and 4 died of asphyxia from massive pulmonary haemorrhage on the third or fourth day of disease. There was no clinical jaundice or renal involvement. I saw two such cases, both fatal, in Malaya before the work undertaken by Mackay-Dick and Robinson (1957).

Also in Indo-china the French (excerpts selected and translated from Le Service de Santos En Indochine, 1946-1954) found that leptospirosis was endemic in the Delta areas. Military operations in marshy zones and rice paddies had a high incidence of infection. It was a serious problem in the French prisoners of the Viet Minh (Allen et al, 1968). The French found essentially the same species of leptospira that werefound in Malaya.

To date leptospirosis has not been found by the Americans to be a significant military problem in Vietnam (Alexander, 1966, personal communication and Buescher $1969 \mathrm{a}$, personal communication) but it is suggested that it is probably more common than is reported. Allen et al (1968) in their paper on the clinical picture of leptospirosis in American soldiers in Vietnam predict that 'Alert physicians who fully evaluate the non-specific symptom complex of headache, myalgia, conjunctival suffusion and gastrointestinal complaints - with urinary abnormalities - should be rewarded by making the clinical diagnosis with increasing frequency.

The question may be posed why do the American Forces in Vietnam have such a low incidence of leptospirosis (10 per cent of cases of PUO) vis-a-vis the British Security Forces in the Malayan Emergency namely 35 per cent of all febrile illnesses (McCrumb et al, 1957). Our experience is that the amount of leptospirosis is directly correlated with the amount of jungle duty. Therefore the likely answer to the above mentioned question is that in jungle warfare the British live in defended positions in the jungle for a matter of months and patrol from there; whereas the relatively low incidence of leptospirosis in the United States Forces in the Republic of Vietnam may be directly related to their mode of transport to and from primary battle sites. Patrols commonly commence on high ridges from a forward fire base to which troops are airlifted, rather than at the base of hills or ridges where men must move upwards. While there are no hard facts to establish this firmly, it seems to be a reasonable working assumption (Buescher, 1969b, personal communication). In other words the incidence of leptospirosis in British Security Forces in Malaysia and in American Forces in Vietnam is correlated with duration of jungle duty, that is, with duration of constant exposure to this disease in leptospiral environments.

\section{Conclusions}

In leptospirosis, in which the natural history is initially a septicaemia, and where an appropriate bactericidal drug is available, the advantages of early diagnosis and the prompt institation of an adequate drug regimen are self evident. To this end a knowledge of leptospiral environments, of the protean manifestations of this disease and of the territorial/occupational/residential history, as well as particular care to establish the day of the illness, are of special significance; as is, of course, the danger of overtreatment and so the avoidance of all stimulants with special reference to vasoconstrictors. 
The order of the day is penicillin therapy given early enough, in large enough doses, often enough and long enough with fluid and electrolyte balance combined with otherwise masterly inactivity; but prednisone may be considered as a 'cover' over the first 24 hours of penicillin therapy so as to suppress some of the alarming features of the penicillin-leptospiral reaction without necessarily depriving it of its diagnostic value.

\section{Epilogue}

It is to be hoped that the lessons from these experiences are to be an exception to the Hegelian view that peoples and governments have never learned anything from history or acted according to its lessons. In other words:

'Those who ignore

the lessons of history

are condemned

to repeat them,

George Santayana.

TAPLIN J. L. (1966). Personal Communication.

Annex A

\section{Leptospirosis-Sarawak Operations}

Reference A-LFB 12.20/3 Med dated 6th June 1966.

Reference B-40 RM 13/5/8 dated 12th June 1966.

Reference $B$ gives the outline facts concerning a patrol of ' $A$ ' Company of this Commando in Sarawak during late October and early November 1965.

This letter in amplification shows the problems which arose from the operational angle.

3 Troop were on patrol in the border area near Plaman Mapu-in the Serian district of the 1st Division. When crossing a river two rifles were dropped in the water. After all 21 members of the patrol had dived in relays - the weapons were recovered.

As the patrol was still close to base they returned and after drying out-resumed their patrol the next day. They returned after 5 days-all men still being fit.

On the 9th or 10th day after the incident one man went sick and on the following day two further men became ill. They were seriously sick and needed evacuation.

No further cases occurred during the next two days and I decided that an important patrol operation should commence. This operation involved 3 Troop and another subunit and was designed to last up to eight days in an extremely remote area from which casualty evacuation by helicopter would be very difficult indeed.

It was appreciated that further cases of lepto might occur in 3 Troop and the patrol was therefore ordered to lie up in a forward base area for 24 hours to see if they did so. The march to this forward base was very hard going and during it--two men did become ill. There was an LS at the forward base and they were evacuated by helicopter. This was on the 14th day after exposure.

That night a further man went sick. This made a total of 6 to date. Included were two junior NCOs. With the possibility of further cases occurring-making the troop ineffective and with the problem of evacuation once the patrol had moved from the forward base - I had no alternative but to visit them and order them to return to Plaman Mapu. 
On the 16th day after exposure-a further man went sick and one more on the 18 th and 21 st days. This brought the total to 9.

Even a mild case of lepto makes a man unfit for active patrolling for several weeks. For some time after apparent recovery he is liable to have a relapse if he takes violent exercise.

I am certain now that preventive medical treatment must be given as soon as possible after the man has been exposed to conditions which are known to be potential lepto sources.

Annex B

GARROD, J.M.C. (1966). Personal Communication. Extract from Reference B of Annex A.

\section{Leptospirosis}

The additional information we can provide on the incident is as follows-

The river was 5 feet deep, it was in spate after a dry period of weather.

Every man of the patrol of 21 was equally exposed-The men dived in relays for the weapons; the diving lasted for four hours; the men were fit and rested-they had left the Company base on this day to start the patrol; they had patrolled about 5 miles; the men had been wet about two hours before the incident; they continued wet for a further two hours, having no dry clothes.

The final count of cases we believe to be nine.

\section{REFERENCES}

Alexander, A. D. (1966). Personal Communication.

Allen, G. L., Webber, D. R. and Russell, P. K. (1968). Milit. Med. 275.

BABUDIERI, B. (1957). Zbl. Bakt. 168, 208.

Baker, H. J. (1965). Milit. Med. 130, 1101.

BAKer, H. J. and Tigert, W. (1967). Personal Communication.

Buescher, E. L. (1969a and 1969b). Personal Communication.

Cook, A. T. (1959). Lancet ii, 81.

De Lajudie, P. and Bygrod, E. R. (1953). Med. trop. 35, 981.

Delahousse, J., Rousihon, J. P., Boyer, G. and Bordes, F. P. (1961. Med. Trop. $21,38$.

DoherTy, R. L. (1955). Aust. Ann. Med. 4, 53.

Doherty, R. L. (1960). Lancet i, 58.

EXCERPTS-Selected and translated from Le Service de Santos En Indochine. 1945-1954.

Garrod, J. M. C. (1966). Personal Communication.

Gsell, O. (1966). Ann. Soc. belge. Med. trop. 46, 203.

Leading Article (1960). Lancet i, 1333.

McCrumb, F. R. Jnr., Stockard, J. L. Robinson, C. R., Turner, L. H. Levis, D. G., Maisey, C. W., Lelleher, M. F., Gleisher, C. A. and Smadel, J. W. (1957). Amer. J. trop. Med. Hyg. 6, 238.

MACKAY-Dick, J. and WatTs, R. W. E. (1949). Lancet i, 907.

MACKAY-Dick, J. and Robinson, J. F. (1957). J. roy. Army med. Cps 103, 186.

MACKAY-DiCK, J. and RoBinson, J. F. (1959a). Lancet i, 100.

MACKAY-DiCK, J. and RoBINSON, J. F. (1959b). Lancet ii, 515.

MaCKAY-Dick, J. (1969). M. D. Thesis. University of Edinburgh.

Moorhouse, J. (1966). Personal Communication.

Spinu, V. T., Trinh, T. H. Q., V.O., U. H., Nouyen, S. Q., Chu, X. L., LI, V. T. and Nguyen, W. A. (1963). Arch. roum. Path. exp. 22 (44), 1081

TAPlin, J. L. (1966). Personal Communication.

TElford, S. B. (1966). Personal Communication.

TURNER, L. H. (1967). Trans. roy. Soc. trop. Med. Hyg. 61, 842.

TuRner, L. H. (1968). Trans. roy. Soc. trop. Med. Hyg. 62, 880.

Turner, L. H. (1969). Brit. med. J. i, 231.

Wang, C. N., Johm, L. Chang, T. F., Cheng, W. J., Luo, M. Y. and Hung, A. T. (1965). China, med. J. 84, 283.

WeEKS, D. G. (1966). Personal Communication.

WHO Chronicle (1968). 22, 159.

Relevant Literature

Control of Communicable Diseases in Man. An official report of the American Public Health Association, Ninth Edition 1960, and Tenth Edition 1965.

Chung, H. L., Ts'oA, W. C., Mo, P. S. and Lyen, C. (1963). Transplacental or congenital infection of leptospirosis. Clinical and experimental observations. China med. J. 82, 777. 